\title{
Percepção sobre a importância da formação profissional por treinadores de judô de elite
}

\author{
Percepetion on the importance of vocational training for elite judo coaches
}

DOI: $\underline{\text { http://dx.doi.org/10.36453/2318-5104.2018.v16.n1.p13 }}$

\author{
Antonio Carlos Tavares Júnior ${ }^{1,2}$, Alexandre Janotta Drigo ${ }^{1}$ \\ ${ }^{1}$ Universidade Estadual Paulista Júlio de Mesquita Filho (UNESP/RC) \\ ${ }^{2}$ Centro Universitário Anhanguera (UNIFIAN/Leme)
}

\begin{abstract}
RESUMO
O estudo objetiva responder qual a importância, atribuída por treinadores de judô de elite, com relação a formação profissional para suas atuações. Foi utilizada uma abordagem qualitativa, podendo ser classificado como estudos de casos múltiplos. Participaram 8 treinadores de judô, selecionados intencionalmente. Utilizou-se de uma entrevista, com dois momentos diferentes: uma parte estruturada e outra semiestruturada. A amostra foi composta de técnicos jovens ( $37,4 \pm 3,8$ anos), mas que contam com resultados expressivos. Todos os treinadores participantes da pesquisa são graduados em Educação Física, sendo que 6 deles são pós-graduados (4 especialistas e 2 Mestres). Constatamos que, para essa população, a formação profissional foi primordial para a atuação como técnico esportivo.
\end{abstract}

PALAVRAS-CHAVE: Judô; Treinador; Formação profissional.

\section{ABSTRACT}

This paper aims to report what is the importance elite judo coaches give to vocational training, in order to plain, prescript and control the training process. The paper is using a qualitative approach, and can be classified as a multiple case study. Eight judo coaches have been intentionally selected to take part of the research. Interviews have been performed with the coaches in two different moments: the first part was structured and the second part was semi structured. This study sample was composed by young coaches ( $37.4 \pm 3.8$ years), who have already conquer expressive results in their carriers. They all have physical education degrees, while six of them are post-graduated (four specialists and two masters). We could observe that, for this group, the vocational training has always been of essential importance in their carriers as sportive coaches.

KEYWORDS: Judo; Coach; Vocational training. 


\section{INTRODUÇÃO}

Ao sistematizar, selecionar, aplicar e aprimorar técnicas samurais do antigo ju-jitsu no Japão, Jigoro Kano, em 1882, idealizou e criou uma nova modalidade de luta e esporte - o judô - que, posteriormente, em Tóquio -1964 integraria o programa olímpico, tornando-se, atualmente, uma modalidade esportiva disseminada em todo mundo. Em 2016, nos Jogos Olímpicos do Rio de Janeiro, foram medalhistas atletas de 26 países diferentes (COI, 2016).

No Brasil, o esporte é praticado por cerca de 2.000 .000 de pessoas (NUNES; RUBIO, 2012) e vem sendo apontado pela mídia brasileira como uma das grandes potências competitivas no cenário internacional, muito por conta das medalhas conquistadas em Jogos Olímpicos, alçado a carro chefe dos últimos Jogos Olímpicos RIO2016 (RAMIL, 2016). Inclusive, um reality show da modalidade foi produzido e transmitido por um tradicional programa de esportes dominical, em uma grande rede de Tv aberta (GONÇALO JÚNIOR, 2017). Esse aumento na popularidade traz atenção para os atletas e também para seus treinadores que são os responsáveis pelo planejamento e preparação que culmina com os bons resultados.

Com relação aos treinadores de judô no Brasil, sabe-se que a formação se desenvolveu por meio de um modelo de transmissão passado de mestres para os aprendizes, através de demonstração e reprodução de golpes, contragolpes, esquivas e combinações, sendo a repetição dos movimentos a principal maneira de aperfeiçoamento (AZEVEDO et al., 2004; CAVAZANI et al., 2013; SILVA et al., 2008). Drigo (2009) chamou essa forma de transmissão de conhecimento de artesanato, por sua similaridade às escolas de ofício do medievo europeu, caracterizado pela relação mestre/discípulo. Rugiu (1998) aponta três características básicas que auxiliam na definição do processo artesanal das escolas de ofício, e que Drigo (2009, p. 396), sintetiza como: os aprendizes em essência aprendem fazendo; apresentam uma imagem valorizada do mestre; as atividades práticas são consideradas tão formativas do caráter quanto os estudos formais.

Todavia, estudos recentes apontam que a formação acadêmica do treinador esportivo não pode ser menosprezada, pois estão atreladas aos processos e resultados de estudos que se orientam para 0 desenvolvimento de uma ou mais áreas, desenvolvendo competências, atitudes críticas fundamentadas, abertura a novas ideias e a capacidade de encarar os limites do seu próprio conhecimento (ROSADO et al., 2008). Inclusive, esse conhecimento é essencial para acompanhar a evolução científica, pois pode influir diretamente em maiores aplicações práticas com rigor científico. E atualmente essa premissa faz cada vez mais sentido, pois existe uma crescente produção acadêmica no judô, mesmo sendo, ainda, muito menor que a produzida para outros esportes. Os autores mais produtivos e aqueles com mais grupos são filiados a universidades de Japão, França e Brasil (PESET et al., 2013), inegavelmente, três das principais potências atuais da modalidade, o que tende a não ser coincidência, inclusive os três países melhores classificados, nessa respectiva ordem no último Campeonato Mundial de Judô (IJF, 2017).

Outras características são exigidas aos treinadores contemporâneos, que não são suportadas apenas pela formação prática, como aspectos fisiológicos e pedagógicos do esporte, por isso a formação universitária tem sido apontada como importante componente na formação dos treinadores esportivos, por conta do seu amplo corpo de conhecimento, recursos e possibilidades de pesquisas e debates sobre o tema (BANACK et al., 2012; JONES et al., 2012; MORGAN et al., 2012). De fato, espera-se que o treinador seja culto, correspondendo às expectativas dos atletas e que tenha capacidade para desenvolver processos de auto formação e de inovação, competências que estão relacionadas a uma formação profissional/acadêmica cada vez mais elevada (ROSADO; MESQUITA, 2009).

Mesmo que a produção acadêmica sobre a formação de treinadores esportivos seja cada vez mais vasta, ainda existe uma lacuna relacionada a formação específica de algumas modalidades esportivas, incluindo o judô. Dessa maneira, o presente estudo objetivou responder qual a importância atribuída por treinadores de judô de elite com relação a formação profissional para o planejamento, prescrição e controle do processo de treinamento? 


\section{MÉTODOS}

O presente estudo usou de uma abordagem qualitativa, podendo ser classificado como estudos de casos múltiplos, sendo submetido e aprovado pelo Comitê de Ética e Pesquisa (CEP) da UNESP, assim como seu instrumento investigativo (Protocolo $n^{\circ} 0607$ e Parecer $n^{\circ}$ 081/13).

Participaram dessa pesquisa 8 treinadores de judô. Eles concordaram em participar, após contato e ciência do Termo de Consentimento Livre e Esclarecido (TCLE). A seleção dos sujeitos foi intencional e respeitou pelo menos dois dos seguintes critérios de inclusão: a) ser finalista do Grand Prix Nacional de Clubes; b) ser treinador de atletas da seleção brasileira (a partir da categoria Sub-21 anos); c) ser integrante da comissão técnica da CBJ (a partir da categoria Sub-21 anos).

Todos os participantes eram treinadores de atletas que compuseram a seleção brasileira de judô. Além disso, dois participantes atenderam a todos os critérios de inclusão. Este grupo é extremamente restrito, configurando-se de elite e de referência em relação ao treinamento do judô nacional, sendo que na análise inicial do perfil desejado para o estudo, menos de 20 treinadores brasileiros foram listados.

Com a necessidade de se criar uma forma de aproximação da realidade com a temática da pesquisa, optou-se pela utilização de uma entrevista, contendo dois momentos: uma parte estruturada, para identificação pessoal, compôs o primeiro momento; enquanto no segundo, uma entrevista semiestruturada foi utilizada para investigar a formação profissional. Os instrumentos de pesquisa foram encaminhados a especialistas da área de Educação Física e Esportes, para apreciação pelos pares enquanto a viabilidade e adequabilidade do questionário

Os procedimentos de coletas ocorreram em 4 momentos diferentes, aos quais chamaremos de rounds:

Round 1: Contato inicial (feito por e-mail ou telefone), apresentação do pesquisador, explicação dos motivos para a escolha do participante e objetivos do estudo;

Round 2: Apresentação do TCLE e aceitação para participação;

Round 3: Coleta de dados através da aplicação das entrevistas (feitas pessoalmente ou por videoconferência);

Round 4: Apresentação da transcrição da entrevista e conferência por parte do participante, com correção ou aceitação do texto.

É importante frisar que todos os participantes aceitaram o texto transcrito sem modificações.

\section{RESULTADOS E DISCUSSÃO}

A amostra foi composta de técnicos do sexo masculino, jovens $(37,4 \pm 3,8$ anos), mas que contam com resultados expressivos em suas carreiras. Todos os sujeitos também são ex-atletas, com títulos conquistados em nível nacional e até internacional e com longo tempo de prática dentro da modalidade (entre 21 e 35 anos). São 6 técnicos do Estado de São Paulo, 1 do Rio de Janeiro e 1 de Minas Gerais. Todos os treinadores participantes da pesquisa são graduados em Educação Física, sendo que 6 deles são pós-graduados (4 especialistas e 2 Mestres). O Quadro 1 apresenta as características dos treinadores estudados.

Constatamos que, para essa população, a formação profissional foi primordial para a atuação como técnico esportivo. O Quadro 2 demonstra isso, em resposta à indagação: "Como e em que pontos sua formação acadêmica colaborou para sua função de técnico de Judô?"

Com relação à formação continuada, nenhum treinador fez algum curso específico para atuação com o judô, entretanto 4 participantes (T1, T2, T3 e T4) citam um novo curso promovido pelo COB (Comitê Olímpico Brasileiro) e ABT (Academia Brasileira de Treinadores), para treinadores de judô, do qual um dos participantes é discente (T2). Os participantes T5, T6 e T7 não fizeram menção ao curso em questão. Sobre esse curso, e a formação continuada em si, o Quadro 3 ilustra as reflexões dos participantes. 
Quadro 1. Características dos treinadores de judô estudados.

\begin{tabular}{|c|c|c|c|c|c|}
\hline Sujeito & Idade & Graduação & Formação* & $\begin{array}{l}\text { Tempo de } \\
\text { atuação }\end{array}$ & Principais Resultados \\
\hline T1 & 39 & 5음 Dan & Especialização & 25 anos & $\begin{array}{c}\text { Medalhistas em Pan-americanos e } \\
\text { Copas do Mundo }\end{array}$ \\
\hline T2 & 39 & 2음 Dan & Graduação & 12 anos & $\begin{array}{c}\text { Medalhistas em Pan-americanos e } \\
\text { Copas do Mundo }\end{array}$ \\
\hline T3 & 32 & 1음 Dan & Mestrado & 10 anos & $\begin{array}{l}\text { Medalhistas em Pan-americanos e } \\
\text { Copas do Mundo }\end{array}$ \\
\hline T4 & 34 & 2음 Dan & Especialização & 06 anos & $\begin{array}{l}\text { Classificação de Atletas em } \\
\text { Seletivas Nacionais }\end{array}$ \\
\hline T5 & 41 & 3음 Dan & Mestrado & 13 anos & $\begin{array}{c}\text { Medalhistas em Sul-americanos e } \\
\text { Copas do Mundo }\end{array}$ \\
\hline T6 & 42 & 4음 Dan & Especialização & 18 anos & $\begin{array}{c}\text { Medalhistas em Jogos Olímpicos e } \\
\text { Campeonatos Mundiais }\end{array}$ \\
\hline T7 & 33 & 10 Dan & Graduação & 6 anos & $\begin{array}{l}\text { Classificação de Atletas em } \\
\text { Seletivas Nacionais }\end{array}$ \\
\hline T8 & 39 & 1음 Dan & Especialização & 2 anos & Medalhistas em Copa do Mundo \\
\hline
\end{tabular}

* Em Educação Física e/ou áreas afins.

Quadro 2. Percepção da Importância da formação profissional na atuação como treinadores de judô.

\begin{tabular}{|c|c|}
\hline Sujeito & Motivo \\
\hline $\mathrm{T} 1$ & $\begin{array}{l}\text { Colaborou muito. Antes de fazer educação física eu trabalhava com criança pequena, mui- } \\
\text { to pequena. Hoje eu comecoo a trabalhar o processo competitivo com } 11 \text { anos. Tanto que } \\
\text { meu tema do TCC na faculdade foi sobre especialização precoce. Depois que me formei } \\
\text { na pós-graduação comecei entender mellor também o trabalho de complementação do } \\
\text { treinamento, a parte fisiológica, da questâo da preparaçấo física. }\end{array}$ \\
\hline T2 & $\begin{array}{l}\text { A formação acadêmica abriu muitas portas. Não tem como pensarmos só no judô, a parte } \\
\text { cientifica é muito importante, até para planejar o treinamento. Quantificar e planejar é o } \\
\text { que mais me ajuda. }\end{array}$ \\
\hline T3 & $\begin{array}{l}\text { No meu caso eu vejo como } 80 \% \text { do meu trabalho a minha formação acadêmica. Como eu } \\
\text { já atuava como técnico quando eu comecei com a faculdade, desde a graduação eu fui } \\
\text { buscar um "know how" que me permitisse utilizar na prática. Sempre fui muito crítico com } \\
\text { relação às práticas que tinham comigo. Entâo fui buscar um conhecimento acadêmico para } \\
\text { modular e fomentar a minha prática como técnico. }\end{array}$ \\
\hline T4 & $\begin{array}{l}\text { Bom, em vários sentidos. Desde a possibilidade de entender melhor o treinamento em to- } \\
\text { dos os sentidos: parte fisica, técnica, tática e até mesmo como proceder com as faixas } \\
\text { etárias diferentes. }\end{array}$ \\
\hline T5 & $\begin{array}{l}\text { Depois que entrei na graduação, pelo menos para a base, comec } \\
\text { não eram bem daquela forma que eu estava desenvolvendo com } \\
\text { a mudar meu estilo. Comecei a perceber que estava agindo com } \\
\text { exagerava um pouco. Estudo muito sobre periodização e acho que } \\
\text { reciclagem. }\end{array}$ \\
\hline T6 & $\begin{array}{l}\text { Na época que eu aprofundei na fisiologia e que eu tive um conteúdo mais aprofundado } \\
\text { sobre o atleta e sobre o treinamento que tive uma maior colaboração para minha atuação. }\end{array}$ \\
\hline T7 & $\begin{array}{l}\text { Eu não consigo pensar em planejamento de treinamento, sem pensar na parte científica, na } \\
\text { fisiologia, no processo de recuperação. É essencial. }\end{array}$ \\
\hline T8 & $\begin{array}{l}\text { Em geral, temos uma tendência em tentar reproduzir o que, supostamente, deu certo co-- } \\
\text { nosco enquanto atleta, aquilo que deu resultado. A formação profissional dá condiçôes de } \\
\text { você repensar essas práticas às quais você foi submetido, tornando-se a principal referên- } \\
\text { cia de nossas práticas. }\end{array}$ \\
\hline
\end{tabular}

Com relação à formação continuada, nenhum treinador fez algum curso específico para atuação com o judô, entretanto 4 participantes (T1, T2, T3 e T4) citam um novo curso promovido pelo COB (Comitê Olímpico 
Brasileiro) e ABT (Academia Brasileira de Treinadores), para treinadores de judô, do qual um dos participantes é discente (T2). Os participantes T5, T6, T7 e T8 não fizeram menção ao curso em questão, mas citam cursos promovidos por universidades ou trabalhos acadêmicos realizados sobre o tema, como forma de contribuição para a atuação profissional. Sobre esse curso, e a formação continuada em si, o Quadro 3 ilustra as reflexões dos participantes.

Quadro 3. Formação continuada dos treinadores de judô.

\begin{tabular}{|c|c|}
\hline & es \\
\hline T1 & $\begin{array}{l}\text { [...] Depois que você faz faculdade, os cursos se tornam irrelevantes. É até uma questão } \\
\text { que discuto com o presidente da federação, ele é meu amigo pessoal. Alguns cursos deve- } \\
\text { riam ser banidos para quem já tem uma certa formação [...] Agora o COB promoveu um. } \\
\text { Inclusive tomei conhecimento depois de encerradas às inscrições. Eu não sei dimensionar } \\
\text { a condição disso, mas eu tenho acesso as pessoas que estãa conduzindo o curso. Mas, eu } \\
\text { acho que mais importante do que ter o curso, é sua formação acadêmica. }\end{array}$ \\
\hline T2 & $\begin{array}{l}\text { [...] Estou fazendo o curso da ABT (Associação Brasileira de Treinadores) e está colaboran- } \\
\text { do bastante [...] E foi muito legal para podermos nortear nosso treinamento. Porque eles } \\
\text { estão colocando alguns problemas técnicos que estão ocorrendo na ponta que são oriun- } \\
\text { dos da base. Eles estão falando que tem muito atleta da ponta que está com problemas } \\
\text { de fundamento técnico, e aí acaba limitando o atleta de estar melhorando tecnicamente } \\
\text { e taticamente. [...] Aqui no clube eles cobram muito essa atualização. Eles sempre trazem } \\
\text { profissionais de fora para estarem dando cursos pra gente [...]. }\end{array}$ \\
\hline T3 & $\begin{array}{l}\text { [...] agora está tendo um que considero muito bom que é promovido pelo COB. Infelizmente } \\
\text { eu acabei perdendo os prazos de inscrições. Curso fomentado pelo COB e pelo que eu pude } \\
\text { observar da grade curricular e dos professores me pareceu muito bom [...]. }\end{array}$ \\
\hline T4 & $\begin{array}{l}\text { Hoje eu sei que existe o curso da Academia Brasileira de Treinadores, promovido pelo COB. } \\
\text { Acho que é único realmente voltado para treinamento de judô. }\end{array}$ \\
\hline T5 & $\begin{array}{l}\text { Curso específico para o técnico de judô não fiz. Mas a minha dissertação eu fiz com tempo } \\
\text { de reação, com fadiga. Eu comparei isso com diferentes tempos de luta no judô. Acho que } \\
\text { isso me ajudou bastante. }\end{array}$ \\
\hline T6 & $\begin{array}{l}\text { A base, o fundamento tive na academia que comecei [...] Na época que estudei no Japão, o } \\
\text { curso era voltado para as artes marciais, mas eu entrei na faculdade mesmo com o objetivo } \\
\text { de ser atleta, então a parte acadêmica em si, ficou bem restrita [...] Posteriormente acom- } \\
\text { panhei o grupo da USP, onde tínhamos uma discussão bem aprofundada sobre os trabalhos } \\
\text { que na época eram voltados ao judố [...]. }\end{array}$ \\
\hline T7 & $\begin{array}{l}\text { [...] olha, acho que o que me ajuda é eu ter me formado e estudado sobre treinamento mes- } \\
\text { mo, fiz uns cursos para faixa-preta, mas acho que não contribuiu em nada, só para pegar a } \\
\text { faixa mesmo. Não tinha nenhuma novidade prática e nada acadêmico. }\end{array}$ \\
\hline T8 & $\begin{array}{l}\text { Eu participei de alguns congressos, cursos quando estava cursando a faculdade, uns cursos } \\
\text { da USP, uns cursos de formação modular para esporte de combates, mais alguns congres- } \\
\text { sos relacionados ao esporte. }\end{array}$ \\
\hline
\end{tabular}

\section{DISCUSSÃO}

Não é possível estabelecer se o aceite em participar da pesquisa tem relação com a formação profissional dos sujeitos, pois esse quesito não era um dos critérios de inclusão. Entretanto, mesmo não se tendo buscado isso, a amostra é composta por treinadores que são profissionais de educação física e ou pós-graduados e que conotam como crucial esse quesito em suas atuações como técnicos de judô. É importante ressaltar que esse é um grupo de destaque do judô brasileiro e que não é possível encontrar muitos treinadores que apresentem os mesmos desempenhos, assim podemos estar assistindo ao surgimento de uma nova realidade, na qual a formação profissional é tão ou mais importante que a formação prática. O destaque brasileiro na produção científica aplicada ao judô (PESET et al., 2013) é mais um reflexo de que, provavelmente, estamos passando por um período de transformações na prática da modalidade e em suas formas de treinamento.

Em estudos anteriores, a característica artesanal do judô brasileiro era marcante e delimitava o processo de ensino-aprendizagem e formação de atletas no esporte (DRIGO, 2009; DRIGO et al., 2011). O 
grupo estudado apresenta duas características marcantes: grande experiência dentro do esporte (inclusive como atletas) e boa qualificação profissional, quesito esse que mostra uma alteração do estado anterior, para uma fase que caminha em direção ao profissionalismo, ao menos no que tange ao alto rendimento. Podemos notar que estes treinadores têm uma graduação no judô relativamente baixa ( 5 técnicos são 1ㅇo ou 2o Dan) e que conferem ao conhecimento científico, obtido através dos cursos de graduação ou pós-graduação na área de Educação Física, o principal motivo para o sucesso em seus trabalhos, fato que contrasta com realidades apresentadas anteriormente (CAVAZANI et al., 2013; DRIGO et al., 2011; SILVA et al., 2008). Assim, percebemos que a relação de formação do mestre artesão, que no judô, segundo Drigo e Cesana (2011), seria exemplificado pela graduação da faixa, está sendo complementada, por estes treinadores, por uma formação de caráter profissional, através de cursos superiores e valorização da ciência.

Sabemos que a qualificação dos treinadores esportivos é um fator preponderante para o êxito competitivo (PLATONOV, 2008). Essa importância fica clara ao observarmos grandes investimentos em programas de formação de treinadores em várias partes do mundo (LYLE, 2007; WERTHNER et al., 2012), bem como na preocupação de desenvolver padrões internacionais que permitam a atuação em diversos países (ICCE, 2013). Alguns programas de qualificação do treinador de judô foram realizados nos últimos anos: um curso recente promovido pelo COB e citado por alguns sujeitos e o Curso Nacional de Capacitação para Técnicos de Judô, promovido pela Confederação Brasileira de Judô (CBJ, 2015). Apesar dessas iniciativas poderem ser consideradas um avanço, esses programas ainda são raros, esporádicos e atendem a um pequeno número de treinadores, diferentes dos programas sistematizados, contínuos e atrelados a formação de treinadores de vários níveis implementados pelas potências olímpicas (ICCE, 2013; LYLE, 2007; WERTHNER et al., 2012).

De maneira geral, para esse grupo estudado, a qualificação profissional, ainda é fruto do esforço individual dos treinadores, que, mesmo dotados de vasto conhecimento prático, buscaram formas de fundamentar, completar e aprimorar suas atuações. Ressaltamos que a busca por conhecimento científico desse grupo, como forma de sustentar seus trabalhos, foi entendida como uma atitude pioneira no cenário do judô nacional. Os fomentos com relação à formação continuada, específica para treinadores de judô, por parte da CBJ ou Federações ainda são raros, assim como a aproximação entre essas esferas e as universidades ou o contrário, sendo resultados de ações pontuais. Predominam os tradicionais cursos de cunho prático e transmissão artesanal de conhecimentos, com pouca inovação científica.

No Brasil, apoiado por Silva et al. (2008) e Cavazani et al. (2013) e confirmado neste estudo, o treinador de judô é um ex-atleta ou um praticante experiente, inclusive por uma exigência das Federações que regem os regulamentos da modalidade. Afinal, para obter o credenciamento técnico o indivíduo necessita obter a faixapreta (FPJ, 2017). Conhecer esses dados é uma forma de aproveitar esse conhecimento prático e incentivar e estruturar um processo de formação profissional, atrelando conhecimento científico, como o estimulado por potências olímpicas na preparação de longo prazo (LLOYD et al., 2016), com treinadores atuando em todas as fases do processo de formação esportiva, já que cada vez mais, apenas o conhecimento prático, mesmo sendo importante, não basta para a preparação esportiva em qualquer esfera (JONES et al., 2012; PLATONOV, 2008).

Todavia, também é importante rediscutir as disciplinas de lutas na graduação e seus conteúdos para atuação como treinador esportivo nas diversas modalidades. Alguns autores afirmam que ainda é raro nas disciplinas de lutas nos cursos de educação física, abordar questões relacionadas a metodologia de ensino e ou de treinamento, restringindo seu conteúdo a componentes práticos (GONÇALVES JÚNIOR; DRIGO, 2011) o que pode ocasionar distanciamento daqueles que já tem maior conhecimento técnico prático e provocar resistência ao conteúdo, daqueles que não tem habilidades práticas necessárias para sentirem-se seguros para atuar nesse campo (ALENCAR et al., 2015). Se pensarmos nas diversas modalidades, cria-se um grande distanciamento entre teoria e prática, sendo que mesmo que a graduação não comporte a especificidade de cada uma, ela teria a função de direcionar o indivíduo na busca e ou seleção pelo conhecimento que seria de suma importância em sua atuação como treinador esportivo de qualquer modalidade, incluindo o judô. Sem cometer o equívoco de desmerecer o conhecimento adquirido ao longo de anos de prática, parece que os outros saberes são tão ou mais importantes para a formação do treinador esportivo. Por isso, é importante que a academia consiga em seus cursos de graduação discutir e preencher essa lacuna, tanto para que exatletas consigam agregar conhecimento em suas futuras atuações, como oportunizar que indivíduos que se interessem pelas modalidades sintam-se seguros para iniciar uma carreira na área, mesmo que em uma equipe 
multidisciplinar.

Ressaltamos a evolução do judô brasileiro, não só em resultados competitivos, mas em suas práticas, outrora muito criticadas (AZEVEDO et al., 2004; DRIGO et al., 2011; SILVA et al., 2008), mas que parecem, hoje, no alto nível, pautando-nos nesse grupo, mais racional e à luz dos pressupostos da ciência. Entretanto, é necessário refletir se o alto rendimento é um universo particular do judô e se as outras vertentes (iniciação, educação, saúde, condicionamento físico e qualidade de vida) atendem à sociedade de maneira adequada, fazendo dos preceitos científicos sua principal fonte de intervenção, abrindo a necessidade de novas investigações.

Faz-se necessário um maior aprofundamento, mas esta pesquisa indica que a formação em educação física e estudos complementares, parecem questões primordiais para a melhoria na atuação de treinadores de judô, pautados no sucesso desses participantes, parecendo plausível associar essas novas configurações com o avanço dos resultados internacionais do judô brasileiro.

\section{CONCLUSÃO}

Nesse sentido, podemos concluir que, para esse grupo, a formação profissional é apontada como primordial para a atuação como treinador de judô. Mesmo que todos tenham muita experiência prática, o estudo aponta para um rompimento com o modelo artesanal, baseado unicamente no "saber fazer" e no conhecimento empírico, em direção a um modelo acadêmico-científico, nessa amostra do judô brasileiro de alto rendimento.

\section{REFERÊNCIAS}

ALENCAR, Y. O.; SILVA, L. H.; LAVOURA, T. N.; DRIGO, A. J. As lutas no ambiente escolar: uma proposta pedagógica. Revista Brasileira de Ciência e Movimento, Brasília, v. 23, n. 3, p. 53-63, 2015.

AZEVEDO, P. H. S. M.; DRIGO, A. J.; OLIVEIRA, P. R.; CARVALHO, M. C. G. A.; SABINO, M. Sistematização da preparação física do judoca Mário Sabino: um estudo de caso do ano de 2003. Revista Brasileira de Ciências do Esporte, Brasília, v. 26, n. 1, p. 73-86, 2004.

BANACK, H.; BLOOM, G.; FALCÃO, W. Promoting long term athlete development in cross country skiing through competency-based coach education: a qualitative study. International Journal of Sports Science \& Coaching, Winchester, v. 7, n. 2, p. 301-15, 2012.

CAVAZANI, R. N.; CESANA, J.; SILVA, L. H.; CRESSONI, F. E. C.; TAVARES JUNIOR, A. C.; ARANHA, A. C. M.; DRIGO, A. J. O técnico de judô: um estudo comparativo após 10 anos da regulamentação da Educação Física. Revista Brasileira de Ciência e Movimento, Brasília, v. 21, n. 3, p. 105-17, 2013.

CBJ. Confederação Brasileira de Judô. Notícias. CBJ abre processo seletivo para Curso Nacional de Capacitação para Técnicos de Judô, set. 2015. Disponível em: <http://www.cbj.com.br/ noticias/5012/cbj-abre-processo-seletivo-para-curso-nacional-de-capacitacao-para-tecnicos-dejudo.html>. Acessado em: 29 de janeiro de 2018.

COI. Comitê Olímpico Internacional. Olimpic judo results: Rio-2016. Disponível em: <https://www. olympic.org/rio-2016/judo>. Acessado em: 15 de dezembro de 2016.

DRIGO, A. J. Lutas e escolas de ofício: analisando o judô brasileiro. Motriz, Rio Claro, v. 15, n. 2, p. 396-406, 2009.

DRIGO, A. J.; CESANA, J. Processo de reestruturação produtiva e econômica, da formação artesanal à industrial e a construção das profissões: recortes com a educação física brasileira, artesanato e profissão. Revista de Educação Skepsis, Rio de Janeiro, v. 3, n. 1, p. 1-20, 2011.

DRIGO, A. J.; SOUZA NETO, S.; CESANA, J.; TOJAL, J. B. A. G. Artes marciais, formação profissional e escolas de ofício: Análise documental do judô brasileiro. Motricidade, Florianópolis, v. 7, n. 4, p. 49-62, 2011.

FPJ. Federação Paulista de Judô. Secretaria 2017. Disponível em: <http://www.fpj.com.br/ secretaria-2017>. Acessado em: 15 de outubro de 2017.

GONÇALO JÚNIOR. 'Popular', judô ganha reality show na TV Globo. Estadão, Ago. 2017. Disponível em: <http://esportes.estadao.com.br/noticias/lutas, popular-judo-ganha-reality-show-na-tv-glo- 
bo,70001950986>. Acessado em: 28 de agosto de 2017.

GONÇALVES JÚNIOR, L.; DRIGO, A. J. A já regulamentada profissão educação física e as artes marciais. Motriz, Rio Claro, v. 7, n. 2, p. 131-2, 2001.

IJF. International Judo Federation. World Senior Championship 2017. Disponível em: <https://www. ijf.org/competition/1463/results>. Acessado em: 15 de outubro de 2017.

ICCE. International Council for Coaching Excellence. International Sport Coaching Framework Version 1.2. Champaign: Human Kinetics, 2013.

JONES, R.; MORGAN, K.; HARRIS, K. Developing coaching pedagogy: seeking a better integration of theory and practice. Sport, Education and Society, Abingdon, v. 15, n. 2, p. 1-17, 2012.

LLOYD, R. S.; CRONIN, J. B.; FAIGENBAUM, A. D.; HAFF, G. G.; HOWARD, R.; KRAEMER, W. J.; MICHELI, L. J.; MYER, G. D.; OLIVER, J. L. National Strength and Conditioning Association position statement on long-term athletic development. Journal Strength and Conditioning Research, Philadelphia, v. 30, n. 6, p. 1491-1509, 2016.

LYLE, J. A review of the research evidence for the impact of coach education. International Journal of Coaching Science, Thousand Oaks, v. 1, n. 1, p. 17-34, 2007.

MORGAN, K.; JONES, R. L.; GILBOURNE, D.; LLEWELLYN, D. Changing the face of coach education: using ethno-drama to depict lived realities. Physical Education and Sport Pedagogy, Glasgow, v. 18, n. 5, p. 1-14, 2012.

NUNES, A. V.; RUBIO, K. As origens do judô brasileiro: a árvore genealógica dos medalhistas olímpicos. Revista Brasileira de Educação Física e Esporte, São Paulo, v. 26, n. 4, p. 667-78, 2012.

PESET, F.; SAPENA, A. F.; VILLAMÓN, M.; GONZÁLES, L. M.; HERRERA, J. L. T.; BENAVENT, R.A. Scientific literature analysis of judo in web of science. Archives of Budo, Krakow, v. 9, n. 2, p. 81-91, 2013.

PLATONOV, V. N. Tratado geral de treinamento desportivo. São Paulo: Phorte; 2008.

RAMIL, T. Judô assume responsabilidade de ser carro-chefe do Brasil na Rio 2016. Reuters, 2016. Disponível em: <http://br.reuters.com/article/sportsNews/idBRKCN1072AD>. Acessado em: 30 de julho de 2016.

ROSADO, A.; MESQUITA, I. Melhorar a performance optimizando a instrução. In: ROSADO, A.; MESQUITA, I. Pedagogia do desporto. Lisboa: Edições FMH, 2009. p. 69- 130.

ROSADO, A.; MESQUITA, I.; JANUÁRIO, N.; BREIA, E. Athlete's retention of coach's instruction on task presentation and feedback. International Journal of Performance Analysis in Sport, Cardiff, v. 8, n. 1, p. 19-30, 2008.

RUGIU, A. S. Nostalgia do mestre artesão. Campinas: Autores Associados; 1998.

SILVA, L. H.; TAVARES JÚNIOR, A. C.; DRIGO, A. J. Produção científica do judô: da academia às academias. Conexões, Campinas, v. 6, n. 1, p. 662-73, 2008.

VERKHOSHANSKY, Y. V. Problemas atuais da metodologia do treino desportivo. Revista Treinamento Desportivo, Curitiba, v. 1, n. 1, p. 33-45, 1996.

WERTHNER, P.; CULVER, D.; TRUDEL, P. An examination of a large scale coach education program from a constructivist perspective. In: SCHINKE, R. (Ed.). Sport Psychology Insights. London: Nova Science Publishers: 2012. p. 337-354.

\section{Autor correspondente: Antônio Carlos Tavares Júnior}

E-mail: professorjuniortavares@hotmail.com

Recebido: 15 de novembro de 2017.

Aceito: 08 de fevereiro de 2018. 